\title{
Right Apical Anterior Fibromuscular Stroma of Prostate
}

National Cancer Institute

\section{Source}

National Cancer Institute. Right Apical Anterior Fibromuscular Stroma of Prostate. NCI

Thesaurus. Code C128580.

The portion of the fibromuscular stroma of the prostate that is located on the anatomical right side of the apical division of the anterior lobe. 